\title{
Maternal demographic and antenatal factors, low birth weight and preterm birth: findings from the mother and child in the environment (MACE) birth cohort, Durban, South Africa
}

Prakash M. Jeena ${ }^{1}$, Kareshma Asharam² ${ }^{2}$ Aweke A. Mitku², Pragalathan Naidoo ${ }^{3}$ and Rajen N. Naidoo ${ }^{2^{*}}$ (D)

\begin{abstract}
Background: Low birthweight (LBW) and preterm birth (PB) remain the leading cause of morbidity and mortality in neonates worldwide. The aim of this study was to identify maternal demographic and antenatal factors associated with PB and LBW among low socio-economic communities.

Methods: Pregnant women ( $n=1099)$ were recruited in the first trimester into the Mother and Child in the Environment (MACE) birth cohort in Durban, South Africa. Maternal factors such as demographic information, health status, residential area, occupational, personal and environmental smoking and biomass fuel use were obtained through standardised interviews, while clinical status was obtained in each trimester and antenatal information on HIV status and treatment, syphilis and conditions such as pregnancy induced hypertension, diabetes etc. was extracted from the antenatal assessments. Key outcomes of interest were preterm birth and low birthweight. The latter data was obtained from the clinical assessments performed by midwives at delivery. Logistic regression models identified factors associated with PB and LBW.

Results: Of the 760 live births, 16.4 and 13.5\% were preterm and LBW, respectively. Mothers who delivered by caesarean section had an increased odds of having LBW babies (Adjusted odds ratio (AOR): 1.7; 95\% CI: 1.1-2.7) and PB (AOR: 1.7, 95\% Cl: 1.1-2.7) versus normal vaginal deliveries. Mothers $>30$ years (AOR: 1.8, 95\% Cl: 1.1-2.9) and current smokers (AOR: $2.7,95 \% \mathrm{Cl}: 1.3-5.8$ ) had an increased odds of having PB babies. Compared to younger mothers and non-smokers respectively. An effect of PB and LBW was seen among mothers with high BMI (25.0$29.9 \mathrm{~kg} / \mathrm{m}^{2}$ ) (PB: AOR: $0.5,95 \%$ Cl: $0.3-0.9$ and LBW: AOR: 0.5, 0.5, Cl: $\left.0.3-0.8\right)$, and obese BMI (> $\left.30 \mathrm{~kg} / \mathrm{m}^{2}\right)(P B:$ : AOR: 0.5, 95\% Cl: 0.3-0.9 and LBW: AOR: 0.4, Cl: 0.2-0.7). Maternal HIV (PB AOR: 1.4 and LBW AOR: 1.2) and history of sexually transmitted infections (PB AOR: 2.7 and LBW AOR: 4.2) were not statistically significant.

\footnotetext{
* Correspondence: naidoon@ukzn.ac.za

${ }^{2}$ Discipline of Occupational and Environmental Health, School of Nursing and

Public Health, Howard College Campus, University of KwaZulu-Natal, Room

321, George Campbell Building, Durban 4041, South Africa

Full list of author information is available at the end of the article
}

C C The Author(s). 2020 Open Access This article is licensed under a Creative Commons Attribution 4.0 International License, which permits use, sharing, adaptation, distribution and reproduction in any medium or format, as long as you give appropriate credit to the original author(s) and the source, provide a link to the Creative Commons licence, and indicate if changes were made. The images or other third party material in this article are included in the article's Creative Commons licence, unless indicated otherwise in a credit line to the material. If material is not included in the article's Creative Commons licence and your intended use is not permitted by statutory regulation or exceeds the permitted use, you will need to obtain permission directly from the copyright holder. To view a copy of this licence, visit http://creativecommons.org/licenses/by/4.0/. The Creative Commons Public Domain Dedication waiver (http://creativecommons.org/publicdomain/zero/1.0/) applies to the data made available in this article, unless otherwise stated in a credit line to the data. 
(Continued from previous page)

Conclusion: Maternal age, cigarette smoking and caesarean delivery were associated with LBW and PB. Findings highlight the need of maternal health interventions to improve new-born health outcomes.

Keywords: Age, Cigarette smoking, Caesarean delivery, Preterm birth, Low birthweight

\section{Background}

Globally, around 30 million low birthweight (LBW) babies and 15 million preterm births (PB) are born annually. This accounts for $23.4 \%$ and $10-11 \%$ of all births, respectively $[1,2]$. In sub-Saharan Africa, adverse pregnancy outcomes including spontaneous abortion, $\mathrm{PB}$ (defined as birth prior to 37 weeks of gestation), LBW (defined as birthweight $<2500 \mathrm{~g}$ ), intrauterine growth retardation (IUGR), small for gestational age (SGA) babies, stillbirths and babies with congenital anomalies are triggered by a broad spectrum of obstetric risk factors such as hypertension, gestational diabetes, tuberculosis and sexually transmitted infections (HIV/AIDS and syphilis) [3-6]. In addition, factors such as poverty, maternal malnutrition, unhealthy living conditions (ambient air pollution and poor sanitary conditions) and tobacco smoke exposure can also play a role in the prevalence of adverse birth outcomes [3-6].

In South Africa, the neonatal mortality rate in 2017 was reported as 12 per 1000 live births [5]. Hypertension, sepsis, haemorrhage and sexually transmitted infections are the main contributing factors for maternal deaths, while among births greater than $500 \mathrm{~g}, \mathrm{~PB}$ (22.9\%), unexplained intrauterine deaths (22.8\%), intrapartum asphyxia (13.4\%) and antepartum haemorrhage (10.6\%) were the leading causes of neonatal deaths [7]. In the province of KwaZulu-Natal (KZN), approximately 180 maternal deaths for every 10,000 live births, and 70 neonatal deaths for every 1000 live births are seen [8].

South African women experience multiple burden of diseases, including those driven by high prevalence of HIV and tuberculosis [6, 7], poor socio-economic status [9] and lack of access to healthcare [10]. The prevalence of tuberculosis in KZN is estimated to be 1094 cases/ 100000 population and $12.9 \%$ of general population in KZN are HIV infected [11].

Despite the evidence supporting socio-economic factors such as maternal education and household income have been associated with low birthweight outcomes, specific household and environmental factors (housing type, biomass exposure and environmental tobacco smoke) have been reported in limited studies in low socioeconomic communities, with a combined high prevalence of established factors such as HIV positive status, poor obstetric history and poor nutritional status. Being able to adjust for these important risk factors, within a sample of low socioeconomic status participants, particularly from the sub-Saharan sub-continent is necessary to understand these risks.

Investigating maternal risk factors that contribute to $\mathrm{PB}$ and LBW are compromised in cross-sectional studies, primarily through recall bias. A cohort, in which females, recruited early in the first trimester, and risk factors assessed throughout the gestational period, provide distinct advantages. Our objective in this study was to describe maternal demographic and antenatal factors that are possibly associated with adverse birth outcomes, $\mathrm{PB}$ and LBW, in a longitudinal Mother and Child in the Environment (MACE) birth cohort in Durban, South Africa.

\section{Methods \\ Selection of communities, study population and study sample}

Pregnant women attending the public sector ante-natal clinics in Durban and surrounding areas (Lamontville, Merebank, Bluff, Austerville, Wentworth, KwaMashu, Newlands East and Newlands West), and who met the inclusion criteria were invited into the cohort. The objective of the MACE study was to determine the risk of environmental pollutant exposure commencing in utero on long term respiratory health of children to 6 years of age and specific outcomes such as asthma.

The selection criteria for subjects to enter this study were as follows:

(a) The recruited participants had to be residing in the geographical area within which the clinic is located, and had to live in this area for the full duration of the pregnancy and follow-up period of up to 5-6 years. The children had to be resident in the communities for the duration of follow-up (to monitor the health of the child from birth up to 6 years of age, and to keep track of their health by gathering information from their Road to Health charts).

(b) Pregnant females had to preferably be less than 20 weeks of gestational age on entry although those presenting before the onset of the 3rd trimester were not excluded.

Women who were asthmatic, hypertensive, diabetic or tested positive for human immunodeficiency virus 
(HIV), syphilis and tuberculosis during their routine ante-natal testing were included. Participating females with complications of pregnancy such as preeclampsia, placenta previa, were also included. Females with multiple pregnancies were excluded from the study.

\section{Sample selection}

We report on the first 1099 recruited pregnant women who had progressed to delivery, experienced a stillbirth or miscarriage, or exited the cohort. The cohort profile (Fig. 1) provides details of the changes from the point of recruitment in April 2013 through to March 2018. The cohort size at each trimesters of pregnancy were 987 (1st trimester), 932 (2nd trimester), 869 (3rd trimester), and 760 (at delivery). Relocation of participants outside the study area and choosing to use clinics closer to their new homes was the single largest reason for the loss to follow-up $(n=257)$. Participants $(n=82)$ who experienced miscarriages and stillbirths or terminating their pregnancy were subsequently removed from the cohort.
Maternal interviews and antenatal clinical assessments Trained interviewers conducted standardised validated face-to-face interviews with all mothers at enrolment, second and third trimesters, as well as monthly telephonic follow-up interviews. The questionnaires included demographic information, antenatal history, place of birth and residential history, occupational history, maternal smoking, exposure to passive cigarette smoke, occupational and environmental exposures, use of biomass fuels, dietary history, pre-existing medical conditions, and past medical and obstetric history. Maternal demographic information was based on responses to questions about marital status (married/living together/ single/divorced/widowed); maternal education (highest grade of school completed/post-high school education/ degree), maternal income (six categories of annual income ranging from no income to US\$7200 or greater) and maternal employment (student/apprentice/at home/ unemployed/disabled/ choice of seven key sectors of work).

Data was captured at the time of the interview using a mobile telephone system, automatically uploading data

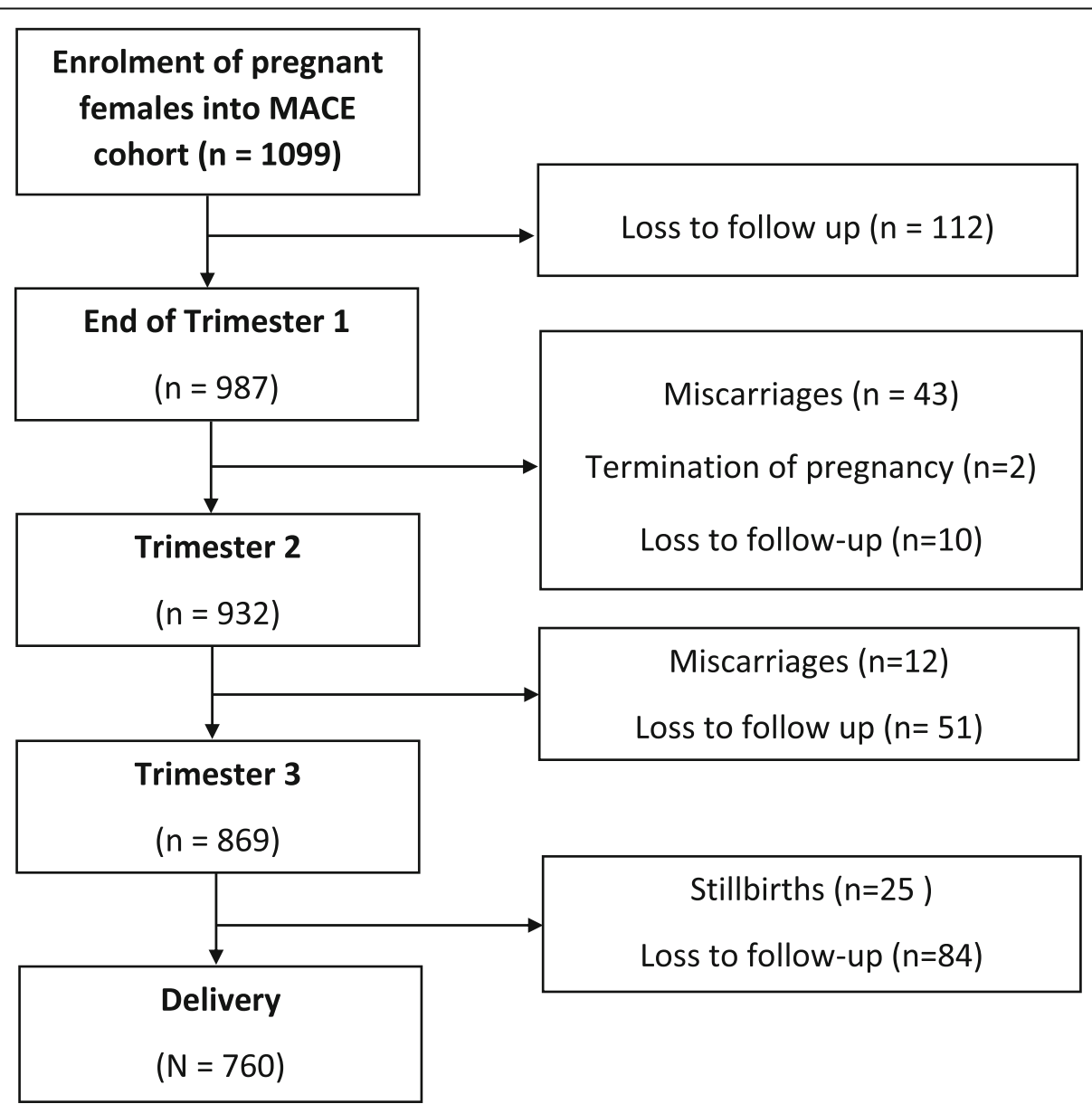

Fig. 1 Cohort profile illustrating hierarchical number of participating women used in the study from the MACE birth cohort 
onto the study database using wireless technology, Mobile Researcher ${ }^{\circ}$.

All questionnaires were made available in English and isiZulu (an indigenous South African language). The isiZulu versions were translated from English and then back translated by a second translator to assure that the instruments are truly equivalent.

A clinical assessment of all enrolled subjects were undertaken in the 3rd trimester of pregnancy. Maternal weight was assessed at enrolment and at delivery. Obesity was evaluated just prior to delivery. In addition, information on routine assessments performed as part of their antenatal follow-up by the public health service was extracted from their records. These included their HIV status and if positive, use of antiretroviral medication, tests for syphilis and diabetes.

\section{Postnatal data collection}

Time of birth and delivery type data were collected by the fieldworkers or extracted from the labour records. Anthropometric measurements and gestational aging were done by the hospital nursery staff using World Health Organisation (WHO) standards. The midwife undertook the measurement of birthweight for each child independently while early ultrasound and postnatal scoring measured gestational age. The person undertaking these measurements was blinded to the study outcomes. This data were used to classify cases into those that were PB $(<37$ completed weeks of pregnancy) and those with LBW $(<2500 \mathrm{~g})$. Gestational age was estimated by a combination of clinical date of last menstrual period, early antenatal ultrasound and the Ballard scoring system postnatally. A combination of prematurity and weight status per individual child was not done.

\section{Statistical analysis}

PB and LBW were the dependent variables of interest. A variety of independent variables were explored through interviews using the standardised instruments. These variables included: socio-demographic variables (marital status; maternal education, maternal income, maternal employment); maternal general, reproductive and obstetric health; residential variables (residential area, housing type; energy type); behaviour and exposure in the current pregnancy (alcohol and smoking history, environmental tobacco smoke exposure, biomass fuel use). In addition, variables with known association with the outcomes of interest were included in our analyses. These included maternal age, HIV positive status, antiretroviral treatment and weight gain during pregnancy.

Standard exploratory data techniques were employed, and descriptive statistics, with frequencies and ranges for categorical, mean and standard deviation (SD) for continuous variables were used to summarize participants' characteristics.

The variables listed above, which, in the bivariate analyses showed a $p$-value $<0.25$ (allowing for joint effects) were included in the multivariate logistic regression models. We ran separate models for each of the dependent variables of interest, $\mathrm{PB}$ and LBW respectively. We additionally included those variables which were clinically important into the models, such as maternal age. We report the crude and adjusted odds ratios (AORs) from the logistic regression models with their 95\% Confidence Interval (CI). A p-value less than 0.05 was considered to be statistically significant. The IBM SPSS statistical software package (version 25.0) was used for all statistical analyses.

\section{Ethics approval and consent to participate}

The study was approved by the Biomedical Research Ethics Committee (BREC) of the University of KwaZuluNatal (UKZN) (BF263/12). All the participants in this study gave written informed consent, participated voluntarily, received no financial incentives, and had the right to withdraw at any stage.

\section{Results}

\section{Baseline demographic data of the cohort}

The majority of mothers were single (79.0\%); $16.7 \%$ had received tertiary education, over $84.0 \%$ did not work, $44.0 \%$ earned a yearly gross income of less than R2 000, with most living in low-income housing communities (67.2\%) and informal settlements (14.7\%) (Table 1). Of those who worked, almost all (98.2\%) had low to middle income jobs (Table 1).

The mean gravida and parity scores were 2.5 (SD: 0.9) and 0.7 (SD: 0.9) respectively, with $44.2 \%$ of mothers having their first pregnancy. (Table 1). Within the sample, 11.5 and $24.1 \%$ were teenage and middle aged pregnancies. While $39.0 \%$ of pregnancies were planned, $22.3 \%$ occurred on contraception usage. Over $70 \%$ of the cohort were sexually active for a minimum of once per week. Of the 613 participants with a previous obstetric history ( $n=965$ previous pregnancies), $24.0 \%$ had bad obstetric outcomes; with the majority (11.3\%) having spontaneous abortions (Table 1).

Almost half (45.3\%) of the pregnant mums lived with people that were cigarette smokers and approximately a third (31.2\%) of them were exposed to environmental tobacco smoke (ETS) (Table 2). A small subset of the cohort were ever-smokers (7.0\%) and only $3.6 \%$ actively smoked during the pregnancy. A small proportion (7.4\%) were ever consumers of alcohol and only $2.7 \%$ actively drank during the pregnancy (Table 2).

A third of the study population were infected with HIV (30.9\%) and all were receiving antiretroviral therapy 
Table 1 Demographic data for pregnant mothers in the MACE birth cohort $\left(n=1099^{\mathrm{a}}\right)$

\section{Characteristics}

Mean age in years (SD)

$26.1(5.9)$

Teenager (15-19 years) (\%)

$87(11.5)$

Prime of fertility (20-30 years) (\%)

487 (64.4)

Middle aged (> 30 years) (\%)

$182(24.1)$

Marital Status

Married (\%)

154 (14.0)

Living together (\%)

$77(7.0)$

Single (\%)

868 (79.0)

Mean number of family members per household (SD)

$3.1(1.6)$

Housing Type

Detached house, Semidetached (\%)

$739(67.2)$

Flat, Terraced flat, Apartment building (\%)

$198(18.0)$

Informal (\%)

$162(14.7)$

Mean number of rooms per household (SD)

$3.3(1.9)$

Ventilation $(n=950)$

Natural (\%)

886 (93.3)

Other (\%)

64 (6.6)

Cooking Energy Source $(n=950)$

Electricity (\%)

$922(97.6)$

Biomass fuels (\%)

$18(2.0)$

Paraffin (\%)

$12(1.3)$

Other (\%)

Mother working ( $n=165,16.1 \%)$

General assistant (\%)

$56(33.9)$

Clerical/administrative (\%)

Machine operator/Supervisor/manager (\%)

$13(7.9)$

Other (\%)

Mothers Education

Never attended or only up to grade 1-7 (\%)

Some High School education (\%)

$269(24.5)$

Matric (high school graduate) (\%)

$61956.3)$

College/ Technikon/ University (\%)

Mothers Annual Income:

$<$ R2000 (\%)

$484(44.0)$

R2001- R10000 (\%)

$195(17.7)$

R10 001 - R30 000 (\%)

$238(21.7)$

$>$ R30 000 (\%)

$121(11.0)$

Refused to answer (\%)

$61(5.6)$

Mean Gestational week at enrolment (SD)

$11.6(3.5)$

Mean Gravida (SD)

$2.5(0.9)$

Mean Parity (SD)

$0.7(0.9)$

Primigravida (\%)

$486(44.2$

Planned pregnancy (\%)

439 (39.0)

Use of contraceptive in the past year (\%) 
Table 1 Demographic data for pregnant mothers in the MACE birth cohort $\left(n=1099^{\mathrm{a}}\right)$ (Continued)

\begin{tabular}{|c|c|}
\hline \multicolumn{2}{|l|}{ Characteristics } \\
\hline Pregnant on contraception (\%) & $242(22.0)$ \\
\hline \multicolumn{2}{|l|}{ Sexual relationship with baby's father (\%) } \\
\hline For some months (\%) & $176(16.0)$ \\
\hline For some Years (\%) & $923(84.0)$ \\
\hline \multicolumn{2}{|c|}{ Sexual intercourse during the 4 weeks before pregnancy } \\
\hline Refused to answer (\%) & $67(6.1)$ \\
\hline$>3$ times a week (\%) & $445(40.4)$ \\
\hline $1-2$ times a week (\%) & $332(30.2)$ \\
\hline$<1$ time a week (\%) & $255(23.2)$ \\
\hline \multicolumn{2}{|c|}{ Outcomes of previous pregnancies $(n=965)^{\mathrm{b}}$ in 613 mothers } \\
\hline Live birth (\%) & $801(83.0)$ \\
\hline Spontaneous Abortion (\%) & $109(11.3)$ \\
\hline Termination of pregnancy (\%) & $15(1.6)$ \\
\hline Ectopic pregnancy (\%) & $20(2.1)$ \\
\hline Still birth (Macerated and fresh) (\%) & $4(0.4)$ \\
\hline Postnatal Death (\%) & $21(2.2)$ \\
\hline Patients with bad obstetric history $(n=613)(\%)$ & $148(24.1)$ \\
\hline
\end{tabular}

(ART), while $15 \%$ tested positive for syphilis. The prevalence of hypertension, gestational diabetes, tuberculosis and asthma were extremely low (Table 2). The mean weight gain for mothers across the first to the third trimester of pregnancy was 6.3 (SD: $6.1 \mathrm{~kg}$ ) (Table 2).

\section{Birth outcomes}

From the enrolled cohort of 1099 cases, a total of 760 (70.8\%) live births resulted. As expected, the incidence of miscarriages were higher in the first trimester compared to the second trimester of pregnancy $(4.0 \%$ versus $1.1 \%$ respectively). There were $2.3 \%$ of mothers who experienced stillbirths during the third trimester. The occurrence of neonatal and infants deaths were low at 0.7 and $1.4 \%$ respectively (Table 3 ). Over $16.4 \%$ of mothers delivered $\mathrm{PB}$ and $13.5 \%$ of babies that were delivered were LBW $(<2500 \mathrm{~g}) ; 0.6 \%$ were $<1500 \mathrm{~g}$. (Table 3).

\section{Factors associated with PB and LBW}

From the bivariate analyses, variables of household risk (location, type or energy type) and socio-demographic variables (marital status; maternal education, maternal income, maternal employment) did not reach statistical significance, and were therefore not included in the logistic regression models.

Mothers aged > 30 years (AOR: 1.8, 95\% CI: 1.1-2.9), current smokers (AOR: 2.7, 95\% CI: 1.3-5.8) and caesarean deliveries (AOR: 1.7, 95\% CI: 1.1-2.7) had statistically significant increased odds ratios for $\mathrm{PB}$. Although not significant, mothers that were teenagers (15-19 years) (AOR: 1.2, 95\% CI: 0.6-2.3), were HIV positive (AOR: 1.4, 95\% CI: $1.0-2.2$ ), and with a history of tuberculosis (AOR: 2.0, 95\% CI: 0.6-6.6) and sexually transmitted infections (AOR: 2.7, 95\% CI: 0.6-12.2) also had increased odds ratios for PB babies. Conversely, overweight mothers (BMI: $25.0-29.9 \mathrm{~kg} / \mathrm{m}^{2}$ ) (AOR: 0.5, 95\% CI: 0.3-0.9), obese mothers (BMI: $>30 \mathrm{~kg} / \mathrm{m}^{2}$ ) (AOR: 0.5, 95\% CI: 0.3-0.9) and mothers with a low BMI $\left(<18.5 \mathrm{~kg} / \mathrm{m}^{2}\right)$ (AOR: 0.9, 95\% CI: 0.4-2.4) did not present with increased odds of having $\mathrm{PB}$ babies (Table 4).

Mothers that had caesarean deliveries had an increased odds ratio for LBW babies (AOR: 1.7, 95\% CI: 1.1-2.7), when compared to those with normal vaginal deliveries. Although not significant, pregnant mothers who were teenagers (AOR: 1.6, 95\% CI: 0.93.1) and middle age (AOR: 1.7, 95\% CI: 1.0-2.9), current smokers (AOR: 1.9, 95\% CI: 0.8-4.3), low BMI (AOR: 1.3, 95\% CI: 0.5-3.3), having a history of sexually transmitted infections (AOR: 4.2, CI: 1.018.3,), being HIV positive (AOR: 1.2, 95\% CI: $0.8-$ 2.0 ), or having pregnancy induced hypertension (AOR: 1.2, 95\% CI: 0.1-10.6) also had increased odds of LBW babies. Conversely, overweight (AOR: 0.5, CI: 0.3-0.8) and obese mothers (AOR: 0.4, CI: 0.2-0.7) and having syphilis did not appear to influence the outcome. (Table 4). 
Table 2 Maternal behavioural and pregnancy factors among the pregnant females in the MACE birth cohort

\begin{tabular}{|c|c|}
\hline & N (\%) \\
\hline \multicolumn{2}{|l|}{ Alcohol and Smoking factors $(n=869)$} \\
\hline Presence of cigarette smokers in home & $413(45.3)$ \\
\hline Passive Smoking & $271(31.2)$ \\
\hline Mother Ever Smoked & $61(7.0)$ \\
\hline Current smoker & $31(3.6)$ \\
\hline Ever Alcohol use & $64(7.4)$ \\
\hline Current Alcohol use & $23(2.6)$ \\
\hline \multicolumn{2}{|l|}{ Prevalence of co-morbid diseases $(n=880)$} \\
\hline$H I V^{a}$ & $261(30.9)$ \\
\hline Syphilis ${ }^{b}$ & $90(15)$ \\
\hline TB & $16(1.8)$ \\
\hline $\mathrm{PIH}$ & $15(1.7)$ \\
\hline Other STI's & $9(1.0)$ \\
\hline Diabetes & $5(0.6)$ \\
\hline Mean weight gain (SD) & $6.3(6.1)$ \\
\hline \multicolumn{2}{|l|}{ Maternal BMI at trimester I } \\
\hline Low BMI $\left(<18.5 \mathrm{~kg} / \mathrm{m}^{2}\right)$ & $33(4.4)$ \\
\hline Normal BMI (18.5-24.9 kg/m²) & $252(33.7)$ \\
\hline High BMI $\left(25-29.9 \mathrm{~kg} / \mathrm{m}^{2}\right)$ & $216(28.9)$ \\
\hline Obese & $247(33.0)$ \\
\hline \multicolumn{2}{|l|}{ Delivery type } \\
\hline NVD & $491(64.6)$ \\
\hline Caesarean & $269(35.4)$ \\
\hline
\end{tabular}

\section{Discussion}

This South African birth cohort study in Durban, found a strong association of maternal smoking during pregnancy, middle aged pregnancies, caesarean section deliveries and low BMI with preterm births. An equally interesting finding was that of a protective effect against both $\mathrm{PB}$ and $\mathrm{LBW}$ of a high BMI among pregnant mothers. The association of maternal smoking and $\mathrm{PB}$ was against the background of a low prevalence of current smoking.

These findings are replicated in other studies. A previous South African study showed that maternal ethnicity, height, BMI, socioeconomic status, and antenatal tobacco and alcohol use were significant modifiable predictors of birthweight [12]. Maternal tobacco use throughout pregnancy was associated with LBW [13], PB [14], and SGA births [13-15]. In most African countries, maternal knowledge on the harmful effects of tobacco use in the manifestation of adverse perinatal outcomes are extremely limited [16]. In our study, a
Table 3 Birth outcomes in the current pregnancy in the MACE birth cohort $(n=1074)$

\begin{tabular}{|c|c|}
\hline Birth Outcomes & N (\%) \\
\hline \multicolumn{2}{|l|}{ First trimester $^{a}$} \\
\hline Miscarriage & $43(4.0)$ \\
\hline Termination of pregnancy & $2(0.2)$ \\
\hline \multicolumn{2}{|l|}{ Second trimester ${ }^{\mathrm{b}}$} \\
\hline Miscarriage & $12(1.1)$ \\
\hline \multicolumn{2}{|l|}{ Third trimester ${ }^{c}$} \\
\hline Still birth & $25(2.3)$ \\
\hline Live births & $760(70.8)$ \\
\hline Death & $22(2.1)$ \\
\hline Neonatal Death ( $<28$ days) & $7(0.7)$ \\
\hline Infant Death (28 days-1 year) & $15(1.4)$ \\
\hline \multicolumn{2}{|l|}{ Gestational Age $(n=760)$} \\
\hline Preterm birth ( $\leq \mathbf{3 7}$ weeks) & $125(16.4)$ \\
\hline Normal birth (38-42 weeks) & $632(83.3)$ \\
\hline Postdate birth (> 42 weeks) & $3(0.4)$ \\
\hline \multicolumn{2}{|l|}{ Birth Weight $(n=760)$} \\
\hline WLBW $(<1000 \mathrm{~g})$ & $2(0.3)$ \\
\hline ELBW (1001 g-1500 g) & $2(0.3)$ \\
\hline LBW (1501- $2499 \mathrm{~g})$ & $98(12.9)$ \\
\hline Normal birth weight (2500 g-4000 g) & $620(81.5)$ \\
\hline High birth weight (> $4000 \mathrm{~g}$ ) & $38(5.0)$ \\
\hline \multicolumn{2}{|c|}{$\begin{array}{l}\text { Notes: }{ }^{\text {a }} \text { Loss to follow up in the first trimester }=112(10.5) . \\
\text { b Loss to follow up in the second trimester }=55(5.2) . \\
\text { c Loss to follow up in the third trimester }=63(5.9) \text {. } \\
\text { WLLBW Very, very low birth weight; } E L B W \text { Extreme low birth weight; } L B W \text { Low } \\
\text { birth weight; } L G A \text { Large for gestational age }\end{array}$} \\
\hline
\end{tabular}

strong association between mothers that were active smokers and PB outcomes was observed. Active smokers were also at increased odds of delivering LBW babies compared to non-smokers, although this association was not significant).

Increasing maternal age is also an independent risk factor for PB and LBW delivery. Studies amongst Americans of different race and ethnic groups, have shown that middle age mothers ( $>30$ years) were most at risk of delivering LBW babies [17, 18]. Teenagers (15-19 years) also had a significantly increased risk of delivering LBW babies as compared those at prime of fertility (25-29years) while teenage and middle age expecting mothers were at a significantly higher risk of delivery PB babies compared to those at prime of fertility [19]. In our study, an association between middle age mothers and PB outcomes was observed, and although not significant, teenage and middle age mothers were also at risk of delivering LBW babies. In other studies adverse birth outcomes was most prevalent amongst middle age primigravidas 
Table 4 Factors associated with Preterm Birth and Low Birth Weight $(n=760)$

\begin{tabular}{|c|c|c|c|c|}
\hline & Crude Odds Ratio & $p$-value & Adjusted Odds Ratio (95\% Cl) & $p$-value \\
\hline \multicolumn{5}{|l|}{ Preterm Birth } \\
\hline \multicolumn{5}{|l|}{ Maternal age } \\
\hline Prime fertility age (20-30 years) & 1 & & 1 & \\
\hline Teenager (15-19years) & 1.2 & 0.5 & $1.2(0.6-2.3)$ & 0.6 \\
\hline Middle aged (> 30 years) & 1.7 & 0.02 & $1.8(1.1-2.9)$ & 0.01 \\
\hline \multicolumn{5}{|l|}{ Maternal BMl at trimester 1} \\
\hline Normal BMI $\left(18.5-24.9 \mathrm{~kg} / \mathrm{m}^{2}\right)$ & 1 & & 1 & \\
\hline Low BMI $\left(<18.5 \mathrm{~kg} / \mathrm{m}^{2}\right)$ & 1.4 & 0.4 & $0.9(0.4-2.4)$ & 0.9 \\
\hline High BMI $\left(25-29.9 \mathrm{~kg} / \mathrm{m}^{2}\right)$ & 0.6 & 0.03 & $0.5(0.3-0.9)$ & 0.02 \\
\hline Obese $\left(>30 \mathrm{~kg} / \mathrm{m}^{2}\right)$ & 0.6 & 0.03 & $0.5(0.3-0.9)$ & 0.01 \\
\hline Past history of tuberculosis & 3.5 & 0.02 & $2.0(0.6-6.6)$ & 0.3 \\
\hline Past history of sexually transmitted infections & 2.6 & 0.2 & $2.7(0.6-12.2)$ & 0.2 \\
\hline Syphilis & 0.3 & 0.02 & $0.4(0.1-0.9)$ & 0.04 \\
\hline \multicolumn{5}{|l|}{ Hypertension } \\
\hline \multicolumn{5}{|l|}{ Normotensive } \\
\hline Chronic & 0.7 & 0.8 & $0.8(0.09-6.7)$ & 0.8 \\
\hline $\mathrm{PIH}$ & 1.1 & 0.9 & $0.5(0.06-4.2)$ & 0.5 \\
\hline HIV positive & 1.4 & 0.1 & $1.4(1.0-2.2)$ & 0.1 \\
\hline Current Smoker & 3.22 & 0.001 & $2.7(1.3-5.8)$ & 0.01 \\
\hline \multicolumn{5}{|l|}{ Delivery Type } \\
\hline Normal delivery & 1 & & 1 & \\
\hline Caesarian section & 1.54 & 0.03 & $1.7(1.1-2.7)$ & 0.01 \\
\hline \multicolumn{5}{|l|}{ Low Birth Weight } \\
\hline \multicolumn{5}{|l|}{ Weight gain } \\
\hline Normal & 1 & & 1 & \\
\hline $\operatorname{High}(>6.3 \mathrm{~kg})^{\mathrm{a}}$ & 0.74 & 0.2 & $0.6(0.4-1.03)$ & 0.07 \\
\hline \multicolumn{5}{|l|}{ Maternal age } \\
\hline Prime fertility age (20-30 years) & 1 & & 1 & \\
\hline Teenager (15-19 years) & 1.7 & 0.1 & $1.6(0.9-3.1)$ & 0.1 \\
\hline Middle aged (> 30 years) & 1.4 & 0.1 & $1.7(1.0-2.9)$ & 0.07 \\
\hline \multicolumn{5}{|l|}{ Maternal BMl at trimester 1} \\
\hline Normal (18.5-24.9) & 1 & & 1 & \\
\hline Low BMI $(<18.5$ kg/m²) & 1.7 & 0.2 & $1.3(0.5-3.3)$ & 0.5 \\
\hline High BMI $\left(25-29.9 \mathrm{~kg} / \mathrm{m}^{2}\right)$ & 0.5 & 0.01 & $0.5(0.3-0.8)$ & 0.01 \\
\hline Obese $\left(>30 \mathrm{~kg} / \mathrm{m}^{2}\right)$ & 0.5 & 0.02 & $0.4(0.2-0.7)$ & 0.002 \\
\hline Past history of sexually transmitted infections & 3.3 & 0.09 & $4.2(1.0-18.3)$ & 0.06 \\
\hline Syphilis & 0.7 & 0.4 & $1.0(0.6-1.7)$ & 0.9 \\
\hline \multicolumn{5}{|l|}{ Hypertension } \\
\hline Normotensive & 1 & & 1 & \\
\hline Chronic & Not available & & Not available & \\
\hline $\mathrm{PIH}$ & 1.4 & 0.6 & $1.2(0.1-10.6)$ & 0.9 \\
\hline HIV Positive & 1.2 & 0.5 & $1.2(0.8-2.03)$ & 0.4 \\
\hline \multicolumn{5}{|l|}{ Smoking } \\
\hline Non-smoker & 1 & & 1 & \\
\hline
\end{tabular}


Table 4 Factors associated with Preterm Birth and Low Birth Weight ( $n=760)$ (Continued)

\begin{tabular}{lllll}
\hline & Crude Odds Ratio & p-value & Adjusted Odds Ratio (95\% Cl) & $\boldsymbol{p}$-value \\
\hline $\begin{array}{l}\text { Current-smoker } \\
\text { Delivery Type }\end{array}$ & 2.4 & 0.03 & $1.9(0.8-4.3)$ & \\
$\quad$ Normal delivery & 1 & & 1 & \\
$\quad$ Caesarian section & 1.4 & 0.1 & $1.7(1.1-2.7)$ & 0.03 \\
\hline
\end{tabular}

${ }^{a}$ Mean weight gain across the first and third trimester for mothers during this pregnancy

- LBW (Yes = 1, No=0), with "YES" when LBW < $2500 \mathrm{~g}$

CI Confidence interval; BMI Body mass index; Ref Reference; PIH Pregnancy induced hypertension; HIV Human immunodeficiency virus; NVD Normal vaginal delivery

with poor socioeconomic status, tobacco smoke exposure, stress and non-communicable diseases [20].

Although caesarean section emerged as an explanatory factor for both $\mathrm{PB}$ and LBW, it is more likely that these children are at greater risk for adverse birth outcomes during labour and thus emergency delivery of baby was necessary. As compared to normal vaginal delivery, caesarean section is considered more rapid and highly recommended when delivering $\mathrm{PB}$ and LBW babies as it helps reduce the risk of stillbirths and neonatal deaths [21].

Maternal nutrition and gestational weight gain have been considered to be important risk factors for delivering PB (overall, induced and spontaneous) and variable birth weight babies [22-24]. Maternal overweight and obesity did not have an adverse effect for LBW, but not for $\mathrm{PB}$, in developing countries [25]. A meta-analyses of cohort studies have significantly associated maternal underweight with PB and LBW [26]. Other studies found that maternal underweight and poor nutritional status to be risk factors for PB and LBW, while obese pregnant women have a low prevalence of $\mathrm{PB}$ outcomes [27-29]. In our study, maternal overweight and obesity were not associated with $\mathrm{PB}$ and LBW. Our findings highlight the importance of proper maternal nutrition and appropriate weight gain during pregnancy to minimise the risk of adverse birth outcomes.

Even though, majority of mothers in our cohort were from poor socioeconomic backgrounds, our study failed to reproduce the findings from other studies where a significantly higher prevalence of LBW and PB were seen in women that were single and unmarried, and with minimal education and low income [30, 31]. Single, unemployed South African women who have experienced previous miscarriages are at high risk of having unplanned pregnancies [32, 33]. In our cohort, there was a high rate of unplanned pregnancies with $22.3 \%$ of women on contraceptives when they fell pregnant. This could imply contraceptive failure or non-adherence as described by other studies [34, 35].

The prevalence of HIV/AIDS and tuberculosis among pregnant South African women have rapidly increased over the past decades. HIV infected women are at a higher risk of delivering PB and LBW babies [36] and experiencing spontaneous abortion and stillbirth [37] and having early infant deaths [38] as compared to HIV uninfected women. Women who start ART before conception as compared to those who start after, are also at a higher risk of delivering LBW, preterm or very preterm babies [39, 40], experiencing spontaneous abortion, stillbirth, elective terminations and ectopic pregnancies [41], and experiencing unintended pregnancies due to contraceptive failures [42]. Similar adverse birth outcomes have been reported in mothers who had tuberculosis [43, 44]. Although no significant associations were observed in our cohort, maternal HIV infection and history of tuberculosis showed trend towards having PB and LBW outcomes in our study.

The prevalence of other sexually transmitted infections in pregnant South African women is also increasing amongst those $<25$ years of age, unmarried and noncohabiting women [45]. Higher incidence risks of sexually transmitted infections (Chlamydia trachomatis, Neisseria gonorrhoea, Trichomonas vaginalis and syphilis) was found in women who attended urban ante-natal clinics and who experienced perinatal death in their previous pregnancies and these cases have been associated with adverse birth outcomes, especially stillbirths [46, 47]. In Tanzania, mothers with high-titer active syphilis had a very high prevalence of stillbirths and were at a high risk of delivering LBW and PB babies as compared to mothers with other serological stages of syphilis [48]. In unscreened women a high prevalence of stillbirths, PB and other adverse birth outcomes have been attributable to maternal syphilis [49].

In our study, a trend between maternal history of sexually transmitted infections and $\mathrm{PB} / \mathrm{LBW}$ outcomes was observed. In contrast to previous reports, we found no effect of maternal syphilis infection on PB and LBW outcomes. Although the serological staging for syphilis was not determined, we speculate that mothers may have had low-titre infections, which could explain our findings.

\section{Strengths and limitations}

A concern in our study was the high dropout rate of pregnant women from enrolment to delivery mainly due 
to relocation. However, this was likely to be random, and thus not expected to have had an impact on the generalisation of our findings. Furthermore, we did not classify LBW as per gestational age or classify individual cases in relation to the extent of prematurity and its related birth weight. An evaluation of the antenatal risk factors against this classification may be useful. The main strengths of this study were large sample size, the ability to identify modifiable risk factors for $\mathrm{PB}$ and LBW outcomes and use this information to promote health intervention programmes for pregnant women.

\section{Conclusion}

This South African birth cohort study have identified maternal risk factors for PB, including cigarette smoking, middle age ( $>30$ years) pregnancies and low BMI. Maternal HIV infection and other sexually transmitted infections showed a trend towards being risk factors for PB and LBW outcomes. Our findings highlight the need for simple cost-effective intervention programs to educate women on the harmful effects of tobacco use, the optimal age for carrying pregnancies and the importance of proper weight gain during pregnancy. Routine testing women for sexually transmitted infections including tuberculosis during the antenatal period is necessary to minimise the risk of adverse birth outcomes.

\section{Supplementary information}

Supplementary information accompanies this paper at https://doi.org/10. 1186/s12884-020-03328-6.

\section{Additional file 1.}

\section{Abbreviations \\ MACE: Mother and Child in the Environment Birth Cohort; LBW: Low birth weight; PB: Pre-term birth; AOR: Adjusted odds ratio; BMI: Body mass index; HIV: Human Immunodeficiency Virus; SGA: Small for gestational age; AIDS: Acquired Immunodeficiency Syndrome; KZN: KwaZulu-Natal province of South Africa; WHO: World Health Organisation; Cl: Confidence Interval; UKZN: University of KwaZulu-Natal; BREC: Biomedical Research Ethics Committee (of UKZN); ETS: Environmental tobacco smoke; ART: Anti-retroviral therapy}

\section{Acknowledgements}

We wish to acknowledge the Mother and Child in the Environment (MACE) cohort study participants, and all study fieldworkers and nursing staff at the participating clinics and hospitals.

\footnotetext{
Authors' contributions

RNN is the overall PI of the study, conceptualised the study design, together with PMJ, who were jointly responsible for the clinical assessments. KA contributed to the study design, was responsible for fieldwork, data acquisition and management. PN was responsible for the drafting of the manuscript. AAM was the lead for the data analysis, and this was further developed and interpreted by RNN, PMJ, KA and PN. All co-authors commented on and contributed to the advanced drafts of the manuscript, including the final submitted version, and versions subsequently revised through the peer-review process. The author(s) read and approved the final manuscript.
}

\section{Funding}

The Mother and Child in the Environment (MACE) cohort study is funded by the following research funding agencies in South Africa: National Research Foundation (NRF) (grant number: 90550), Medical Research Council (MRC) and the AstraZeneca Research Trust. The funders played no role in the design and conduct of the study, or the data analysis and drafting of the manuscript.

\section{Availability of data and materials}

The datasets generated and analysed during the current study are not publicly available as our ethical approvals does not allow for this. However, should parties be interested in reviewing the data, the corresponding author will be able to approach the institutional ethical board to obtain necessary clearance, following reasonable request.

\section{Ethics approval and consent to participate}

The study was approved by the Biomedical Research Ethics Committee (BREC) of the University of KwaZulu-Natal (UKZN) (BF263/12). All the participants in this study gave written informed consent, participated voluntarily and no financial incentives were provided, and had the right to withdraw at any stage. Consent for the assessment and use of clinical information of the newborns were provided by their mothers. The parents or caregivers of all other participants under the age of 16 provided written consent for their participation.

\section{Consent for publication}

No identifying images or personal clinical data are presented in the manuscript, hence no individual consent for publication was obtained.

\section{Competing interests}

The authors declare no competing interests in the conduct of this study.

\section{Author details}

${ }^{1}$ Discipline of Paediatrics and Child Health, Nelson R Mandela School of Medicine, University of KwaZulu-Natal, Durban, South Africa. ${ }^{2}$ Discipline of Occupational and Environmental Health, School of Nursing and Public Health, Howard College Campus, University of KwaZulu-Natal, Room 321, George Campbell Building, Durban 4041, South Africa. ${ }^{3}$ Discipline of Medical Biochemistry and Chemical Pathology, Howard College Campus, University of KwaZulu-Natal, Durban, South Africa.

Received: 28 June 2019 Accepted: 9 October 2020

Published online: 16 October 2020

\section{References}

1. Louis B, Steven B, Margret N, Ronald N, Emmanuel L, Tadeo N, et al. Prevalence and factors associated with low birth weight among teenage mothers in new Mulago hospital: a cross sectional study. J Health Sci (El Monte). 2016:4(4):192-9.

2. Van den Broek NR, Jean-Baptiste R, Neilson JP. Factors associated with preterm, early preterm and late preterm birth in Malawi. PLoS One. 2014; $9(3): 1-8$.

3. Kinney MV, Kerber KJ, Black RE, Cohen B, Nkrumah F, Coovadia H, et al. SubSaharan Africa's mothers, newborns, and children: where and why do they die? PLoS Med. 2010;7(6):1-9.

4. Khan KS, Wojdyla D, Say L, Gülmezoglu AM, Van Look PF. WHO analysis of causes of maternal death: a systematic review. Lancet. 2006; 367(9516):1066-74.

5. Dorrington RE, Bradshaw D, Laubscher R, Nannan N. Rapid mortality surveillance report 2017. Cape Town: South African Medical Research Council; 2019. ISBN: 978-1-928340-36-2.

6. Black RE, Cousens S, Johnson HL, Lawn JE, Rudan I, Bassani DG, et al. Global, regional, and national causes of child mortality in 2008: a systematic analysis. Lancet. 2010;375(9730):1969-87.

7. The National Perinatal Morbidity and Mortality Committee. Saving Babies 2014-2016 Triennial report on perinatal mortality in South Africa. Pretoria. 2017 (Available at: https://www.westerncape.gov.za/assets/departments/ health/napemmco_triennial_report_2014-2016_saving_babies.pdf. Accessed 14 Oct 2020. 
8. Group SAEDCW. Every death counts: use of mortality audit data for decision making to save the lives of mothers, babies, and children in South Africa. Lancet. 2008;371(9620):1294-304.

9. Ataguba JE, Akazili J, McIntyre D. Socioeconomic-related health inequality in South Africa: evidence from general household surveys. Int J Equity Health. 2011;10(1):1-10.

10. Coovadia H, Jewkes R, Barron P, Sanders D, McIntyre D. The health and health system of South Africa: historical roots of current public health challenges. Lancet. 2009;374(9692):817-34.

11. Kasprowicz VO, Achkar JM, Wilson D. The tuberculosis and HIV epidemic in South Africa and the KwaZulu-Natal Research Institute for Tuberculosis and HIV. J Infect Dis. 2011;1204(4):S1099-101.

12. Budree S, Stein D, Brittain K, Goddard E, Koen N, Barnett W, et al. Maternal and infant factors had a significant impact on birthweight and longitudinal growth in a south African birth cohort. Acta Paediatr. 2017:106(11):1793-801.

13. Abusalah A, Gavana M, Haidich AB, Smyrnakis E, Papadakis N, Papanikolaou $A$, et al. Low birth weight and prenatal exposure to indoor pollution from tobacco smoke and wood fuel smoke: a matched case-control study in Gaza strip. Matern Child Health J. 2012;16(8):1718-27.

14. Hodyl NA, Stark MJ, Scheil W, Grzeskowiak LE, Clifton VL. Perinatal outcomes following maternal asthma and cigarette smoking during pregnancy. Eur Respir J. 2014;43(3):704-16.

15. Miyake $Y$, Tanaka K, Arakawa M. Active and passive maternal smoking during pregnancy and birth outcomes: the Kyushu Okinawa maternal and child health study. BMC Pregnancy Childbirth. 2013;13(1):1-8.

16. Chomba E, Tshefu A, Onyamboko M, Kaseba-Sata C, Moore J, McClure EM, et al. Tobacco use and secondhand smoke exposure during pregnancy in two African countries: Zambia and the Democratic Republic of the Congo. Acta Obstet Gynecol Scand. 2010;89(4):531-9.

17. Reichman NE, Pagnini DL. Maternal age and birth outcomes: data from New Jersey. Int Fam Plann Persp. 1997;29(6):268-95.

18. Aldous MB, Edmonson MB. Maternal age at first childbirth and risk of low birth weight and preterm delivery in Washington state. JAMA. 1993;270(21): 2574-7.

19. Schempf AH, Branum AM, Lukacs SL, Schoendorf KC. Maternal age and parity-associated risks of preterm birth: differences by race/ethnicity. Paediatr Perinat Epidemiol. 2007;21 (1):34-43.

20. Delpisheh A, Brabin L, Attia E, Brabin BJ. Pregnancy late in life: a hospitalbased study of birth outcomes. J Women's Health. 2008;17(6):965-70.

21. Chen Y, Wu L, Zhang W, Zou L, Li G, Fan L. Delivery modes and pregnancy outcomes of low birth weight infants in China. J Perinatol. 2016;36(1):41-6.

22. Lawlor DA, Relton C, Sattar N, Nelson SM. Maternal adiposity-a determinant of perinatal and offspring outcomes? Nat Rev Endocrinol. 2012; 8(11):679-88.

23. Gaillard R, Durmuş B, Hofman A, Mackenbach JP, Steegers EA, Jaddoe WW. Risk factors and outcomes of maternal obesity and excessive weight gain during pregnancy. Obesity. 2013;21(5):1046-55.

24. Surkan PJ, Hsieh CC, Johansson AL, Dickman PW, Cnattingius S. Reasons for increasing trends in large for gestational age births. Obstet Gynecol. 2004; 104(4):720-6.

25. McDonald SD, Han Z, Mulla S, Beyene J. Overweight and obesity in mothers and risk of preterm birth and low birth weight infants: systematic review and meta-analyses. Br Med J. 2010;341:1-20.

26. Han Z, Mulla S, Beyene J, Liao G, McDonald SD. Maternal underweight and the risk of preterm birth and low birth weight: a systematic review and meta-analyses. Int J Epidemiol. 2010;40(1):65-101.

27. Kozuki N, Katz J, LeClerq SC, Khatry SK, West KP, Christian P. Risk factors and neonatal/infant mortality risk of small-for-gestational-age and preterm birth in rural Nepal. J Matern Fetal Neonatal Med. 2014;28(9):1019-25.

28. Hendler I, Goldenberg RL, Mercer BM, lams JD, Meis PJ, Moawad AH, et al. The preterm prediction study: association between maternal body mass index and spontaneous and indicated preterm birth. Am J Obstet Gynecol. 2005;192(3):882-6.

29. Yu Z, Han S, Zhu J, Sun X, Ji C, Guo X. Pre-pregnancy body mass index in relation to infant birth weight and offspring overweight/obesity: a systematic review and meta-analysis. PLoS One. 2013;8(4):1-11.

30. Mohd Zain N, Low WY, Othman S. Impact of maternal marital status on birth outcomes among young Malaysian women: a prospective cohort study. Asia Pac J Public Health. 2015;27(3):335-47.

31. Dang BN, Van Dessel L, Hanke J, Hilliard MA. Birth outcomes among lowincome women — documented and undocumented. Perm J. 2011;15(2):39-43.
32. Haffejee F, O'Connor L, Govender N, Reddy P, Sibiya MN, Ghuman S, et al. Factors associated with unintended pregnancy among women attending a public health facility in KwaZulu-Natal. South Africa S Afr Fam Pract. 2018; 60(3):79-83.

33. Blackstone SR, Nwaozuru U, Iwelunmor J. Factors influencing contraceptive use in sub-Saharan Africa: a systematic review. Int Q Community Health Educ. 2017;37(2):79-91.

34. Hubacher D, Mavranezouli I, McGinn E. Unintended pregnancy in subSaharan Africa: magnitude of the problem and potential role of contraceptive implants to alleviate it. Contraception. 2008;78(1):73-8.

35. McCoy Sl, Buzdugan R, Ralph L, Mushavi A, Mahomva A, Hakobyan A, et al. Unmet need for family planning, contraceptive failure, and unintended pregnancy among HIV-infected and HIV-uninfected women in Zimbabwe. PLoS One. 2014;9(8):1-8.

36. Xiao PL, Zhou YB, Chen Y, Yang MX, Song XX, Shi Y, et al. Association between maternal HIV infection and low birth weight and prematurity: a meta-analysis of cohort studies. BMC Pregnancy Childbirth. 2015;15(1):1-11.

37. Rollins NC, Coovadia HM, Bland RM, Coutsoudis A, Bennish ML, Patel D, et al. Pregnancy outcomes in HIV-infected and uninfected women in rural and urban South Africa. J Acquir Immune Defic Syndr. 2007;44(3):321-8.

38. Brocklehurst $P$, French $R$. The association between maternal HIV infection and perinatal outcome: a systematic review of the literature and metaanalysis. BJOG-Int J Obstet Gy. 1998;105(8):836-48.

39. Ekouevi DK, Coffie PA, Becquet R, Tonwe-Gold B, Horo A, Thiebaut R, et al. Antiretroviral therapy in pregnant women with advanced HIV disease and pregnancy outcomes in Abidjan. Cote d'Ivoire AIDS. 2008:22(14):1815-20.

40. Uthman OA, Nachega JB, Anderson J, Kanters S, Mills EJ, Renaud F, et al. Timing of initiation of antiretroviral therapy and adverse pregnancy outcomes: a systematic review and meta-analysis. Lancet HIV. 2017;4(1):110.

41. Stringer EM, Kendall MA, Lockman S, Campbell TB, Nielsen-Saines K, Sawe F, et al. Pregnancy outcomes among HIV-infected women who conceived on antiretroviral therapy. PLoS One. 2018;13(7):1-12.

42. Schwartz SR, Rees H, Mehta S, Venter WDF, Taha TE, Black V. High incidence of unplanned pregnancy after antiretroviral therapy initiation: findings from a prospective cohort study in South Africa. PLoS One. 2012;(4):1-8.

43. Lin HC, Chen SF. Increased risk of low birthweight and small for gestational age infants among women with tuberculosis. BJOG-Int J Obstet Gy. 2010; 117(5):585-90.

44. Loto OM, Awowole I. Tuberculosis in pregnancy: a review. J Pregnancy. 2012:1-7.

45. Naidoo S, Wand H, Abbai NS, Ramjee G. High prevalence and incidence of sexually transmitted infections among women living in Kwazulu-Natal South Africa, AIDS Res Ther 2014;11(1),1-7.

46. Wilkinson D, Sach M, Connolly C. Epidemiology of syphilis in pregnancy in rural South Africa: opportunities for control. Tropical Med Int Health. 1997; 2(1):57-62.

47. Zhou H, Chen XS, Hong FC, Pan P, Yang F, Cai YM, et al. Risk factors for syphilis infection among pregnant women: results of a case-control study in Shenzhen China. Sex Transm Infect. 2007:83(6):476-80.

48. Watson-Jones D, Changalucha J, Gumodoka B, Weiss H, Rusizoka M, Ndeki L, et al. Syphilis in pregnancy in Tanzania. I. Impact of maternal syphilis on outcome of pregnancy. J Infect Dis. 2002;186(7):940-7.

49. Gomez GB, Kamb ML, Newman LM, Mark J, Broutet N, Hawkes SJ. Untreated maternal syphilis and adverse outcomes of pregnancy: a systematic review and meta-analysis. Bull World Health Organ. 2013;91(3):217-26.

\section{Publisher's Note}

Springer Nature remains neutral with regard to jurisdictional claims in published maps and institutional affiliations. 